\title{
小麦-长穗偃麦草抗白粉病异代换系中一个新的 磷酸丝氨酸氨基转移酶基因的克隆
}

\author{
何道一 ${ }^{\circledR}$ 王洪刚 ${ }^{\circledR}$ \\ (1) 淮北煤炭师范学院生物系, 淮北 235000; (2) 山东农业大学农学院, 泰安 271000. E-mail: daoyi1h@sohu.com)
}

\begin{abstract}
摘要 以抗白粉病的小麦-长穗偃麦草异代换系山农 551 为材料, 在接种小麦白粉病菌 $48 \mathrm{~h}$ 制备样品电 子显微镜观察, 结果表明山农 551 在白粉病菌侵染早期抑制狍子萌发和菌丝生长. 在接种病菌 $48 \mathrm{~h}$ 后提 取 RNA，利用 cDNA RDA 和 RACE 技术克隆 WRP1 和 RPW2 共 2 个基因. BLAST 分析表明该二基因均 是尚未被克隆的新基因. WRP1 没有大的 ORF; RPW2 的翻译产物含有保守的氨基转移酶结构域, 与多种 生物的磷酸丝氨酸氨基转移酶有同源序列, 可以认为是一新的磷酸丝氨酸氨基转移酶基因. Northern 杂 交结果显示在小麦白粉病侵染早期 RPW2 在山农 551 的叶片中就开始表达. RPW2 探针同山农 551 及其 亲本鲁麦 5 号、济南 13 和长穗偃麦草基因组 DNA 进行 Southern 杂交结果显示, 探针与鲁麦 5 号和济 南 13 无杂交信号, 而与山农 551 和长穗偃麦草都有较强的杂交信号, 这表明 $R P W 2$ 来源于长穗偃麦草 基因组.
\end{abstract}

关键词 小麦 长穗偃麦草 白粉病 CDNA RDA 磷酸丝氨酸氨基转移酶

小麦白粉病是小麦主要病害之一，它发生范围 广, 通常能造成 $10 \%$ 以上的减产。近年来，随着单产 水平的提高和采用高产栽培模式, 该病害日趋严重, 对小麦高产稳产构成严重威胁. 尽管化学药物防治 也十分有效, 但从食品和环境安全角度培育抗病品 种仍是最经济有效的措施 ${ }^{[1]}$.

历史上曾培育出许多抗小麦白粉病品种, 但由 于白粉病菌生理小种变异速度快, 抗病品种易丧失 抗病性, 因此, 就要不断地发掘和利用新的抗性资源. 在小麦的近缘野生植物中发现了许多这样的抗病基 因资源, 有些抗病基因已经通过有性杂交的方法转 移到栽培小麦中并培育出抗病品系 ${ }^{[2]}$, 并发掘了一些 与这些抗病基因位点密切相关的分子标记 ${ }^{[3 \sim 5]}$, 但是 关于这些基因位点的组织结构了解甚少，也没有克 隆到与这些位点直接相关的基因. 对这些抗病基因 的本质认识将极大地促进对小麦白粉病抗性机制的 认识和抗病品种的培育.

多年鉴定结果表明，长穗偃麦草(Elytrigia elongatum, $2 n=70$ )对小麦白粉病免疫, 通过有性杂交, 抗病基因可转移到小麦与长穗偃麦草的杂交后代中. 本实验室从其杂交后代中已篮选出多个具小麦白粉 病抗性的异源代换系. 这里我们报道从强抗白粉病 异源代换系山农 551 中利用 cDNA RDA 和 RACE 技 术克隆到来源长穗偃麦草基因组的一个新的磷酸丝 氨酸氨基转移酶基因.

\section{1 材料与方法}

（i ) 植物材料和病原菌. 材料为本室构建的抗 小麦白粉病小麦-长穗偃麦草代换系 551 ((济南 $13 \times$ 长 穗偃麦草) $\times$ 鲁麦 5 号), 白粉病菌种为中国农业科学 院植物保护研究所提供的 15 号小种. 种子播种在已 灭菌的珍珠岩基质中, 在温度为 $25^{\circ} \mathrm{C}$, 空气相对湿度 为 $85 \%$ $90 \%, 2000 \mathrm{Lux}$ 光照条件下培养, 发芽后 $10 \mathrm{~d}$, 将白粉病菌孢子均匀地喷酒在叶片上, 以喷酒无菌 蒸馏水的材料为对照. 接种病菌的材料为 $\mathrm{T}$ (Tracer) 组,未接种病菌的材料为 $\mathrm{D}$ (Driver)组.

(ii) 总RNA提取与测定. 接种病菌后按实验要 求不同时间取材于液氮中冷冻, 总RNA提取采用异 硫氰酸胍法 ${ }^{[6]}$. cDNA-RDA在接种病菌后 $48 \mathrm{~h}$ 取材. RNA纯度和产量用DU-640 蛋白质核酸动力学分析仪 (BECKMAN)测定. RNA 完整性用变性胶电泳检测. 总RNA经不含 RNA酶的DNA酶(Pharmacia) $37^{\circ} \mathrm{C}$ 保温 $10 \mathrm{~min}, 70^{\circ} \mathrm{C} 10 \mathrm{~min}$ 灭活.

(iii) 有限第 1 链逆转录与加尾. 有限第 1 链逆 转录使用 MBI 公司的逆转录试剂盒, $0.5 \mu \mathrm{g}$ 总 RNA 按试剂盒使用说明进行逆转录, 逆转录时间控制在 $10 \mathrm{~min}, 70^{\circ} \mathrm{C}$ 灭活 $10 \mathrm{~min}$ 逆转录酶. $10 \mu \mathrm{L}$ 有限合成第 1 链混合物, $40 \mathrm{U}$ TDT(MBI)和 $5 \mathrm{mmol} / \mathrm{L}$ dATP $37^{\circ} \mathrm{C}$ 保育 $15 \mathrm{~min}, 70^{\circ} \mathrm{C}$ 灭活 TDT $10 \mathrm{~min}$.

(iv) 代表性 $\mathrm{cDNA}$ 库的扩增. 以加尾的有限合 
成的第 1 链产物作模板, 分别以 $\mathrm{P} 2$ 和 $\mathrm{Pm}$ 作 $\mathrm{T}$ 组和 $\mathrm{D}$ 组的引物, $\mathrm{PCR}$ 扩增的条件是: $94^{\circ} \mathrm{C}$ 预变性 $2 \mathrm{~min}$; $94^{\circ} \mathrm{C}, 30 \mathrm{~s}, 42^{\circ} \mathrm{C}, 30 \mathrm{~s}, 72^{\circ} \mathrm{C}, 3 \mathrm{~min}, 25$ 次循环, $72^{\circ} \mathrm{C}$ 延 伸 $10 \mathrm{~min}$. P2: 3'-GAGGCCGTATGAATTCT(17)-5'. Pm: 3'-GCGGCCGCT(17)-5', 5'端生物素标记.

( v ) 杂交、减法与再扩增. $\mathrm{T}$ 组和 $\mathrm{D}$ 组代表性 cDNA 库的扩增产物经纯化后, 按 $1: 20(\mathrm{~T}: \mathrm{D})$ 的比 例在杂交缓冲液中 $68^{\circ} \mathrm{C}$ 杂交 $48 \mathrm{~h}$. 杂交混合物经 50 $\mathrm{mmol} / \mathrm{L}$ EPPS ( $\mathrm{pH}$ 8.5)配制的链霉生物素蛋白和酚/ 氯仿(1: 1)反复抽提, 最终得到减法产物. 取 $5 \mu \mathrm{L}$ 减 法产物, 以 P2 为引物再经 PCR 扩增, 扩增条件同上, 扩增产物纯化后用于下一轮杂交. 从 $2 \%$ 凝胶上切割 经 5 轮杂交、减法和再扩增的产物, 用 Ultrafree-DA (Millipore)回收.

(vi) 序列分析. 回收物与载体 pMD18-T 在 $16^{\circ} \mathrm{C}$ 条件下连结 $30 \mathrm{~min}$. 转化已制备好的感受态细胞, 采 用蓝白斑挑选转化细胞. 挑选出的转化细胞提取质 粒经 PCR 进一步确认插入片段. 对挑选的不同细胞 系分别经上海生物工程公司和宝生物工程(大连)公 司测序. 对已测序列与 GenBank+EMBL+DDBJ+PDB 中的序列经 BLASTn 和 BLASTp 比对分析.

(vii) 基因组DNA 提取与Southern杂交. 按 CTAB法 ${ }^{[7]}$ 分别提取代换系 551，长穗偃麦草、济南 13 和鲁麦 5 号幼叶基因组DNA; 基因组DNA经Hind III 酶解过夜, $0.8 \%$ 琼脂糖凝胶、25 V电泳 $12 \mathrm{~h}$; 尼龙膜 (Amersham)印迹转移 $15 \mathrm{~h} ;{ }^{32} \mathrm{P}-\mathrm{dCTP}$ (福瑞生物工程 公司)标记探针, 以 $\mathrm{cDNA}$ RDA 产物 $R P W 2$ 片段为模 板，采用 PCR 法制备并用 Mircrocon-PCR filter Unites(Millipore)纯化回收探针. 杂交炉(Lab-line)中 $65^{\circ} \mathrm{C}$ 旋转杂交过夜.

(viii) RNA Northern 杂交. 分别提取山农 551 末 接种病菌、接种病菌后 12, 24 和 $48 \mathrm{~h}$ 叶片中的总 RNA, 总 RNA 经变性琼脂糖凝胶电泳分离, 按常规方法印迹 过夜，紫外线照射固定; 探针制备同上; 在分子杂交 炉(LAB-LINE)中 $42^{\circ} \mathrm{C}$ 杂交过夜, 中严谨度洗膜 2 次.

(ix) WRP1 和 RPW2 的RACE分析. 根据WRP1 和RPW2 已测的序列片段, 用DNA Club软件设计 5 -RACE引物, $R P W 2$ 的引物为 $\mathrm{SJ} 1$ 和 $\mathrm{SJ} 2 ; W R P 1$ 的为 $\mathrm{SJ} 3$ 和SJ4. RACE的基本步骤按Frohman ${ }^{[8]}$ 方法进行, 使用的逆转录酶为 SurpScriptTM" $\mathrm{RNaseH}^{-}$ (Invitrogen). $94^{\circ} \mathrm{C}$ 预变性 $50 \mathrm{~s}$, 扩增共 30 次循环, 每 个循环的条件为 $94^{\circ} \mathrm{C}, 30 \mathrm{~s}, 48^{\circ} \mathrm{C}, 150 \mathrm{~s}, 72^{\circ} \mathrm{C}, 3 \mathrm{~min}$.
根据第 1 次 RACE 结果, 重新设计引物 NS1 和 NS4 对 RPW2 和 WRP1 分别进行第 2 次 RACE. RACE 产 物的回收、测序及分析同上, 所有引物由上海生工合 成. 引物序列为:

SJ1: 3'-AGAGTGGGATGAGGCATAGAG-5';

SJ2: 3'-CTCTATGCCTCATCCCACTCT-5';

SJ3: 3'-TGGGACTGGCGGAAGTGTC-5';

SJ4: 3'-GACACTTCCGCCAGTCCCA-5';

NS1: 3'-CGCCTAATGGAGGTTCATG-5';

NS4: 3'-CGGGTAACTCCGTTACAACA-5'.

(X) 电子显微镜样品制备与观察. 白粉病菌接 种 $48 \mathrm{~h}$, 取叶片于 $4 \%$ 的戊二醛中固定, 再经 $1 \%$ 的锇 酸固定; 乙醇梯度脱水; $\mathrm{CO}_{2}$ 临界点干燥仪干燥贴样; IB-5 离子浅射仪镀膜; JEM-1200EX 电子显微镜扫描 观察.

\section{2 结果与分析}

2.1 异源代换系 551 对白粉病菌孢子萌发和菌丝生 长的抑制

经室内和田间接种实验, 山农 551 和长穗偃草对 小麦白粉病具有很强的抗性, 按国际小麦种质鉴定 的 10 级分类标准, 它们的感病等级为 0 . 而山农 551 的亲本济南 13 和鲁麦 5 号都是易感品种, 它们的感 病等级分别为 8 和 7 . 因此, 山农 551 中这种抗性来 自长穗偃麦草. 接种病菌 $48 \mathrm{~h}$ 后, 制备山农 551 及其 不抗病亲本鲁麦 5 号叶片样品进行扫描电子显微镜 观察, 结果见图 1. 从图中可看出, 不抗白粉病的亲 本鲁麦 5 号叶片上菌丝生长繁茂, 而 551 的叶片上狍 子萌发延迟, 菌丝生长缓慢, 长势较弱. 这与抗性接 种实验结果相一致, 同时也表明山农 551 对白粉病的 抗性发生在病菌侵染早期.

\section{2 白粉病侵染早期对异源代换系 551 进行 cDNA- RDA 的结果}

经过 4 轮杂交, 减法产物逐步被富集, 结果见图 2. 第 5 轮杂交减法产物 PCR 扩增后经 $2 \%$ 的琼脂糖 凝胶电泳, 得到距离上非常邻近的 2 条带(图 3), 它们 分别是 333 和 $314 \mathrm{bp}$. 切胶回收并与 $\mathrm{T}$ 载体连结, 转 化大肠杆菌 DH $5 \alpha$, 经蓝白斑篮选, 随机挑取单个白 色菌落, 分别经上海生物工程公司和宝生物工程(大 连)公司测序, 两公司测序结果完全一致, 两片段分 别被命名为 WRP1 和 RPW2 (GenBank 登录号: AY211193, AY211194). 用 BLASTn 序列分析平台对 WRP1 和 RPW2 进行序列同源性分析，在同源性最高 

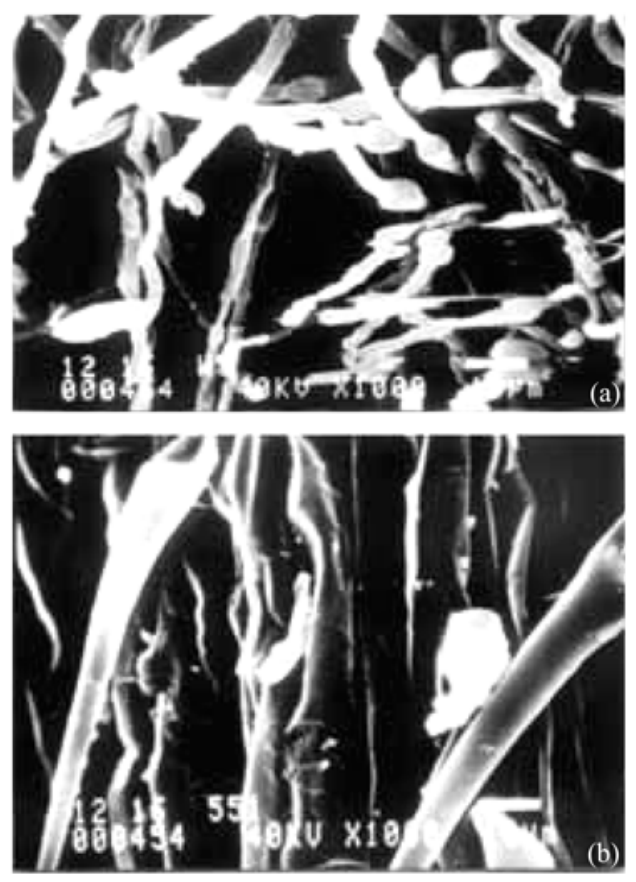

图 1 接种小麦白粉病菌 $48 \mathrm{~h}$ 后叶片电子显微镜扫描结果 (a) 品种鲁麦 5 号; (b) 异代换系山农 551

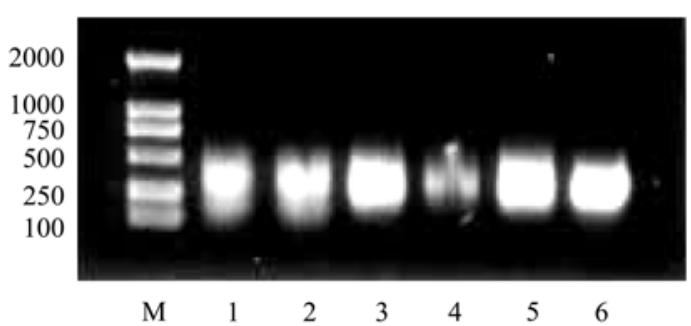

图 24 轮杂交减法结果

$M$ 示 Marker(DL 2000, TaKaRa). 1 和 2 为 $D$ 组和 $T$ 组有限逆转录加尾 后扩增的结果; 3 6 分别为 1 4 轮杂交减法扩增的结果

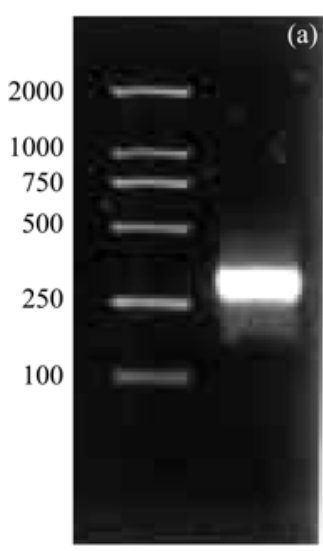

M

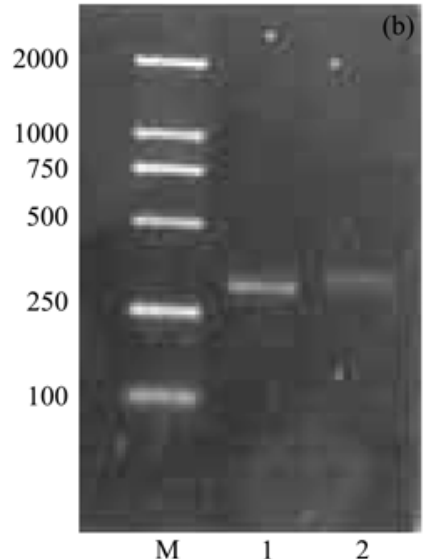

M
的序列中, WRP 1 只与人的一染色体序列有 21 个碱基 相同; RPW2 与老鼠 11 号染色体序列有 19 个碱基相 同. 这表明 WRP1 和 $R P W 2$ 是尚末克隆的新基因.

\subsection{WRP1 和 RPW2 的 5'-RACE 结果}

cDNA RDA 结果是 3'端产物, 根据这个结果设计 了系列引物对 WRP1 和 RPW2 片段进行 5'-RACE. SJ1 和 $\mathrm{SJ} 2$ 为 $R P W 2$ 设计, $\mathrm{SJ} 3$ 和 $\mathrm{SJ} 4$ 为 $W R P 1$ 设计. 当使 用 $\mathrm{SJ} 2$ 和 $\mathrm{SJ} 3$ 进行逆转录并与引物 P2 配对加尾产物 进行 RACE，扩增产物呈弥散状，长度小于 $500 \mathrm{bp}$, 而以 SJ1 和 SJ4 进行 RACE 时，扩增产物也呈弥散状, 但长度超过 $1000 \mathrm{bp}$ (图 4(a)), 这说明了 WRP1 和 $R P W 2$ 的 cDNA 的方向. 据此在 $\mathrm{SJ} 1$ 和 $\mathrm{SJ} 4$ 的上游再 设计 2 个引物 NS1 和 NS4, 以该 2 引物与引物 P2 配 对对 RPW2 和 WRP1 进行第 2 次 RACE, 结果见图 4(b). $W R P 1$ 的 RACE 结果除引物后为 $839 \mathrm{bp}$, 从中未找到 大的 ORF, 该产物尚待进一步研究. RPW2 的 RACE 结果为 $1197 \mathrm{bp}$ (去引物), 编码一磷酸丝氨酸氨基转 移酶.
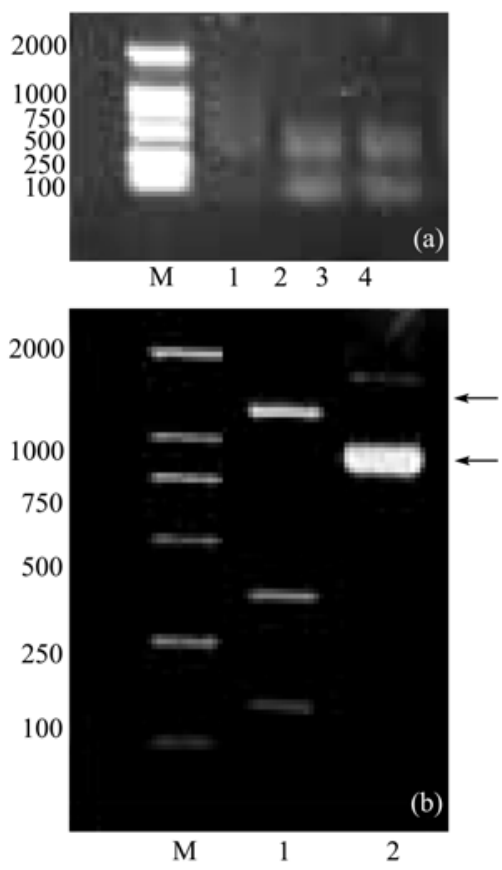

图 42 次 RACE 结果

$M$ 示 Marker(DL 2000, TaKaRa ) (a) 第 1 次 RACE 结果; 1 和 2 分别示 引物 $\mathrm{SJ} 1$ 和 $\mathrm{SJ} 2$ 及 $\mathrm{P} 2$ 对 RPW2 的 RACE 结果; 3 和 4 分别示 $\mathrm{SJ} 3$ 和 $\mathrm{SJ} 4$ 及 P2 对 WRP1 的 RACE 结果. (b) 第 2 轮 RACE 结果, 箭头所指为目 标带; 1 RPW2, 2 RPW1

\subsection{RPW2 是一新的磷酸丝氨酸转移酶基因} 全长 RPW2 的翻译产物为 416 个氨基酸残基的多 (a) 第 5 轮杂交减法后扩增的结果; (b) 切胶后分别再扩增的结果. 1 示 $R P W 2$ 部分; 2 示 WRP1 部分, $M$ 示 Marker(DL 2000, TaKaRa ) 
肽, 其序列为: MAAATTPKSLLRRGGSSLHSAAASFILLPTRAARLSCAAVATPAQSSSSPAAAATPFLFPSGGTGPATLLSVLKRAQAEPVITFLIGFSIMELSQRGKEFDGGIKVHKPADLRALLAVPDTHEVLFLQGGATSQFAAAPLNLWSIQSSTGLVLPIDFVVSGSWSDKAFKKCLLVDGVSVASGKDGKYTSFPPFDAIDVSSQKALSLPLHRGLGIVCASFDKVFPENDFYKLGILVADGARKKLGTYVDVSRFGLIYAGANVPPTGVTIAIVRKDLVGSAQPITPVMLDYKTHADNASLYNTHECFAIYLCGLVFEDLLAQGGLAEVEKKASGSAGILYDDIDASFGGHLCPVEKSVRSLAGVPFTLILYGDFEKQFIAEAAKEGMYQL KGHRSVGGVRAGPHCADYPPGTSLLAGP

对 RPW2 及其翻译产物进行 BLASTn 和 BLASTp 比对分析, 未发现有同样的序列报道, 表明 RPW2 是 一个新的基因序列. 比对分析同时还表明其翻译产 物的 CCD 结构含有氨基转移酶 $\mathrm{v}$ 和 Ser C 的保守结 构域, 并与许多生物的磷酸丝氨酸转移酶有类似的 序列, 因此可以认为 RPW2 是一个新的磷酸丝氨基转 移酶.

\subsection{RPW2 在白粉病菌侵染早期表达}

以 $R P W 2$ 为模板制备探针, 同接种白粉病菌后不 同时间提取的 RNA 进行 Northern 杂交, 结果见图 5. $R P W 2$ 从 $12 \mathrm{~h}$ 就一直有较强的杂交信号, 表明从病菌 侵染时 RPW2 就稳定表达.

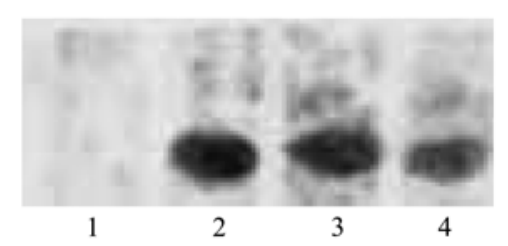

图 $5 R P W 2$ Northern 杂交结果

1 为末接种白粉病菌材料; $2 \sim 4$ 分别为接种白粉病菌后 12,24 和 $48 \mathrm{~h}$. 每泳道 RNA 量为 $20 \mu \mathrm{g}$

\section{$2.6 R P W 2$ 来源于长穗偃麦草基因组}

制备的 RPW2 放射性探针与济南 13, 鲁麦 5 号, 代换系 551 和长穗偃麦草基因组 DNA 进行 Southern 杂交, 结果见图 6. RPW2 与济南 13 , 鲁麦 5 号无任何 杂交信号. RPW2 与代换系 551 和长穗偃麦草都有较 强的杂交信号, 表明 RPW2 来自长穗偃麦草基因组.

\section{3 讨论}

山农 551 是从(济南 $13 \times$ 长穗偃麦草) $\times$ 鲁麦 5 杂交 后代中选育的抗小麦白粉病的异源代换系,细胞遗传 学鉴定表明它是含有长穗偃麦草的染色体组份, 多 年的田间和室内接种试验表明山农 551 表现较强的

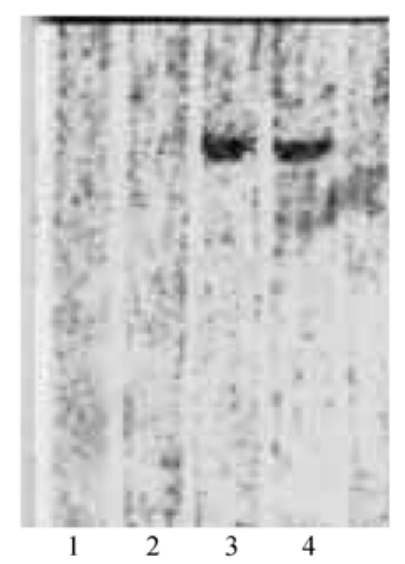

图 $6 R P W 2$ 与基因组 DNA Southern 杂交结果 $1 \sim 4$ 分别为济南 13 , 鲁麦 5 号, 山农 551 和长穗偃麦草

抗小麦白粉病特性, 由于济南 13 和鲁麦 5 号对流行 小种均表现易感, 因此, 这种抗性的获得与来源于长 穗偃麦草的遗传物质相关. 电子显微镜扫描观察结 果与接种试验结果相吻合, 山农 551 延缓病菌孢子萌 发, 抑制菌丝生长. 这表明来源于长穗偃麦草的遗传 物质参与了抗病的早期过程. 弄清来源于长穗偃麦 草基因组中与抗病相关的基因, 对进一步认识植物 的抗病的分子机理和充分利用该抗病基因资源都大 有裨益.

长期进化过程中，植物形成了复杂的抵抗病原 生物侵染的防卫机制. 首先在植物的表层形成机械 性和化学性的防侵染的障碍层. 在植物体内部尚存 在更为复杂的系统性抗病机制, 包括植物 $\mathrm{R}$ 基因与病 原毒基因相互识别相互作用而产生的特异性抗性机 制和更多类型的尚不清楚的非特异性的抗病机制 ${ }^{[9]}$. 这些机制中都涉及到一系列相关基因的表达，这些 基因常与抗病信号分子的产生 ${ }^{[10]}$ 、抗性化合物的形成 [11]、侵染位点细胞程序性死亡以及植物获得系统免疫 性有关 ${ }^{[12]}$.

$\mathrm{R}$ 基因介导的植物抗病机制一直是重点研究内 容, 不仅发现了与病原菌识别相关的植物 $\mathrm{R}$ 基因的蛋 白质结构上的一些特征 ${ }^{[13,14]}$, 而且对植物的抗病网 络及其重要组分和可能的信号分子也有了进一步的 认识 ${ }^{[15 \sim 17]}$. 大麦与其白粉病之间的相互作用被认为 是研究禾本科草本植物与病原微生物相互作用的模 式系统, 通过对这一系统的研究, 许多抗性位点的基 因被克隆, 在基因组中这些位点的基因排列方式及 序列的结构特征被揭示 ${ }^{[18 ~ 20]}$. 然而, 植物其他方面的 抗病机制了解甚少. 近年来诸多的研究结果表明一 些与植物代谢相关的酶在抗性的形成过程中有重要 
作用 ${ }^{[21 ~ 23]}$ ，这种抗性被定义为“酶抗性”. 与 $R$ 基因介 导的抗性相比, 酶抗性可能具有更广的抗病谱, 这对 植物抗病基因工程更为有用.

利用 cDNA RDA 和 RACE 方法, 我们克隆了 2 个 基因即 WRP 1 和 $R P W 2$. 在 WRP1 中没有大的 ORF, 它 还有待于进一步研究与分析. RPW2 的推测的翻译产 物具有保守的氨基转移酶结构域, 其碱基序列与多种 生物的磷酸丝氨酸氨基转移酶基因具有高度的相似 性, 因此认为它是一个新的磷酸丝氨酸氨基转移酶.

磷酸丝氨酸氨基转移酶是过氧化物酶体中植物 光呼吸代谢途径中的酶类, 植物的光呼吸在过氧化 物酶体中产生 $\mathrm{H}_{2} \mathrm{O}_{2}$, 这是重要的抗病信号分子之一, 它能激发植物细胞产生过敏性反应(HR), 进一步诱 导细胞程序性死亡、抗菌物质产生和细胞壁加厚等抗 病反应 ${ }^{[24]}$. Northern 杂交结果表明RPW2 在接种病原菌 后 $12 \mathrm{~h}$ 就大量稳定表达, 这与植物抗病过程中 $\mathrm{H}_{2} \mathrm{O}_{2}$ 迸发在时间上也十分吻合, 但 $R P W 2$ 与一般的光呼吸 途径中的丝氨酸氨基转移酶有何不同? 在抗病过程 中确切作用如何? 这些问题都非常值得深入研究.

在植物的野生种中常表现出一些综合的抗逆性 状，这种抗病特性很难用 $\mathrm{R}$ 基因介导的抗病机制来 解释. Southern 杂交结果表明 RPW2 来源于长穗偃麦 草基因组, 据我们所知, 这是第一个被克隆的来源于 小麦近源野生种基因组的与抗病相关的基因. 它在 这种抗病机制中的作用如何是非常有价值的理论问 题. $R P W 2$ 能否有效地应用于麦类作物抗病基因工程 还取决于对其功能的最终鉴定.

\section{参考文献}

1 刘金元, 刘大钧. 小麦白粉病抗性基因研究进展. 植物病理学 报, 2000, 30(4): 289 295

2 李振声, 容珊, 陈漱阳, 等. 小麦远缘杂交. 北京: 科学出版社, 1985. 1 51

3 Ma Z Q, Sorrel M E, Tanksley S D. RFLP markers linked to powdery mildew resistance genes $\mathrm{Pm} 1, \mathrm{Pm} 2, \mathrm{Pm} 3$ and $\mathrm{Pm} 4$ in wheat. Genome, 1994, 37: 871 875

4 Hartl L, Weiss H, Stephan U, et al. Molecular identification of powdery mildew resistance genes in common wheat (Triticum aestivum L). Theor Appl Genet, 1995, 90: 601 606

5 王心宇, 开增军, 马正强, 等. 小麦抗白粉病基因 Pm6 的 RAPD 标记. 遗传学报, 2000, 27 (12): 1072 1079

6 Clark M S, 主编. 顾红雅, 翟礼嘉, 译. 植物分子生物学实验手 册. 北京: 高等教育出版社. 海德堡: 施普林格出版社, 1998 . 122 124

7 Murray M G, Thompson W F. Rapid isolation of high molecular weight plant DNA. Nucleic Acids Res, 1980, 8: 4321 4325a.com/doi/10.1360/csb2005-50-6-5? (2004-10-12 收稿, 2005-01-28 收修改稿)
8 Frohman M A, Dush M K, Martin G R. Rapid production of full-length cDNA from rare transcripts by amplification using gene-specific oligonucleotide primer. Proc Natl Acad Sci USA, 1988, 85: 8998 9002

9 Dangl J, Jones J D G. Plant pathogens and integrated defence responses to infection. Nature, 2001, 411: 826 833[DOI]

10 Bolwell G P. Role of active oxygen species and NO in plant defense responses. Curr Opin Plant Biol, 1999, 2: 287 294[DOI]

11 Kolomiets M V, Chen H, Gladon RJ, et al. A leaf lipoxygenase of potato induced specifically by pathogen infection. Plant Physiol, 2000, 124: 1121 1130[DOI]

12 Kawasaki T, Henmi K, Ono E, et al. The small GTP-binding protein Rac is a regulator of cell death in plants. Proc Natl Acad Sci USA, 1999, 96: 10922 10926[DOI]

13 Jones D A, Jones J D G. The role of leucine-rich repeat proteins in plant defenses. Adv Bot Res, 1997, 24: 90 166

14 Hammond-Kosack K E, Jones J D G. Plant disease resistance genes. Annu Rev Plant Phys Plant Mol Biol, 1997, 48: 575 607[DOI]

15 Baker B, Zambryski P, Staskawicz B, et al. Signaling in Plant-microbe interactions. Science, 1997, 276: 726 733[DOI]

16 Shirasu K, Lahaye T, Tan M W, et al. A novel class of eukaryotic zinc-binding proteins is required for disease resistance signaling in barley and development in C. elegans. Cell, 1999, 99: 355 366[DOI]

17 Aarts N, Metz M, Holub E, et al. Different requirements for eds1 and NDR1 by disease resistance genes define at least two $\mathrm{R}$ gene-mediated signaling pathways in Arabidopsis. Proc Natl Acad Sci USA, 1998, 95: 10306 10311[DOI]

18 Wei F, Gobelman-Werner K, Morroll S M, et al. The Mla (powdery mildew) resistance cluster is associated with three NBS-LRR gene families and suppressed recombination with a $240-\mathrm{kb}$ DNA interval on Chromosome 5S (1HS) of barley. Genetics, 1999, 153: 1929 1948

19 Feuillet C, Keller B. High gene density is conserved at syntenic 1999, 96: 8265 8270[DOI]

20 Halterman D, Zhou F, Wei F, et al. The MLA6 coil-coil, NBS-LRR protein confers AvrMla6-dependent resistance specificity to Blumeria graminis F. sp. hordei in barley and wheat. Plant J, 2001, 25 (3): 335 348[DOI]

21 Wang H, Hao L, Shung C Y, et al. Adenosine kinase is inactivated by geminivirus AL2 and L2 proteins. Plant Cell, 2003, 15: 3020 3032[DOI]

22 Hao L, Wang H, Sunter G, et al. Geminivirus AL2 and L2 proteins interact with and inactivate SNF1 kinase. Plant Cell, 2003, 15: 1034 1048[DOI]

23 Kang L, Li J, Zhao T, et al. Interplay of the Arabidopsis nonhost resistance gene NHO1 with bacterial virulence. Proc Acad Sci USA, 2003, 100: 3519 3524[DOI]

24 Lamb C, Dixon R A. The oxidative burst in plant disease resistance. Annu Rev Plant Physiol Plant Mol Biol, 1997, 48: 251 275[DOI] loci of small and large grass genomes. Proc Natl Acad Sci USA, 